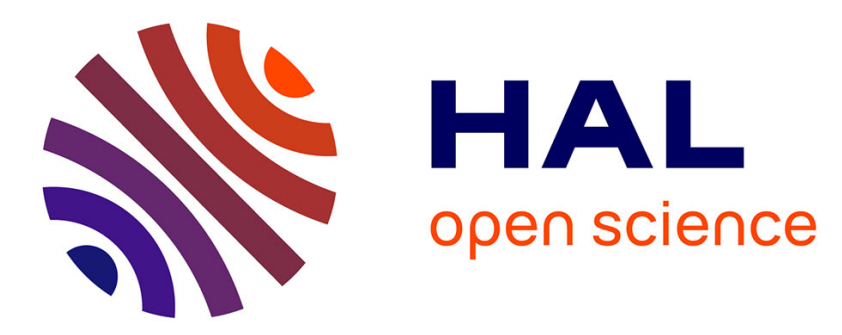

\title{
Thinning increases cone production of stone pine (Pinus pinea L.) stands in the Northern Plateau (Spain)
}

\author{
Daniel Moreno-Fernández, Isabel Cañellas, Rafael Calama, Javier Gordo,
} Mariola Sánchez-González

\section{- To cite this version:}

Daniel Moreno-Fernández, Isabel Cañellas, Rafael Calama, Javier Gordo, Mariola Sánchez-González. Thinning increases cone production of stone pine (Pinus pinea L.) stands in the Northern Plateau (Spain). Annals of Forest Science, 2013, 70 (8), pp.761-768. 10.1007/s13595-013-0319-3 . hal01201519

\section{HAL Id: hal-01201519 \\ https://hal.science/hal-01201519}

Submitted on 17 Sep 2015

HAL is a multi-disciplinary open access archive for the deposit and dissemination of scientific research documents, whether they are published or not. The documents may come from teaching and research institutions in France or abroad, or from public or private research centers.
L'archive ouverte pluridisciplinaire HAL, est destinée au dépôt et à la diffusion de documents scientifiques de niveau recherche, publiés ou non, émanant des établissements d'enseignement et de recherche français ou étrangers, des laboratoires publics ou privés. 


\title{
Thinning increases cone production of stone pine (Pinus pinea $\mathrm{L}$.) stands in the Northern Plateau (Spain)
}

\author{
Daniel Moreno-Fernández • Isabel Cañellas • Rafael Calama • \\ Javier Gordo • Mariola Sánchez-González
}

Received: 3 April 2013 / Accepted: 18 July 2013 /Published online: 23 August 2013

(C) INRA and Springer-Verlag France 2013

\begin{abstract}
- Context Edible stone pine (Pinus pinea L.) nut is a forest product which provides the highest incomes to the owners of stone pine forests.

- Aim The objective of this work is to evaluate the effect of first thinning on growth and cone production in an artificially regenerated stand in order to determine optimum intensity.

- Methods A thinning trial was installed in 2004 to compare two thinning regimes (heavy and moderate) and a control treatment. From 2004 to 2012, six inventories of forest attributes were carried out, and the cone crop was harvested annually. We evaluated the effect of thinnings on growth using repeated measures analysis of variance with a mixed model approach. With regards to cone production, we first estimated
\end{abstract}

Handling Editor: Gilbert Aussenac

Contribution of the co-authors Daniel Moreno-Fernández: data analysis, analysis of results, and writing the manuscript.

Isabel Cañellas: experimental design, discussion of the results, and coordination of the work.

Rafael Calama: participation in the experimental design and discussion of the results.

Javier Gordo: selection of site for the trials and discussion of the results; also provided knowledge of the forests.

Mariola Sánchez-González: supervision of the statistical analysis, discussion of the results, and participation in the writing of the manuscript.

D. Moreno-Fernández $\cdot$ I. Cañellas $\cdot$ R. Calama

M. Sánchez-González

Centre for Forest Research, INIA, Ctra. A Coruña km 7.5,

28040 Madrid, Spain

D. Moreno-Fernández $(\bowtie) \cdot$ I. Cañellas $\cdot$ R. Calama

M. Sánchez-González

Sustainable Forest Management Research Institute, Universidad de

Valladolid \& INIA, Palencia, Spain

e-mail: danielmorenofdez@gmail.com

J. Gordo

Forest Service of Junta Castilla y León, C/Duque de la Victoria 5,

47001 Valladolid, Spain the probability of finding cones in a tree by applying a generalized mixed model and then estimated cone production by using a mixed model, including climatic variables.

- Results We found that thinning had a positive influence on tree diameter increment. Thinning increased the probability of finding cones and cone production. However, significant differences between heavy and moderate thinnings were not found.

- Conclusion We recommend early silvicultural treatments in stone pine stands to favor the development of trees and larger edible pine nut production.

Keywords Mixed models $\cdot$ Logistic regression · Nonwood products $\cdot$ Edible nut $\cdot$ Mediterranean area $\cdot$ Early treatments

\section{Introduction}

Stone pine (Pinus pinea L.) is a species native to the Mediterranean area. Natural or afforested stone pine stands occupy more than 400,000 ha in Spain (Montero et al. 2008). Traditionally, the management of stone pine stands has tried to combine multiple objectives: edible pine nut production, timber, firewood, recreational use, landscaping, and protection against wind erosion on sandy soils. However, pine cones provide high incomes to the forest owners, often more than that associated with timber or firewood, due to the fact that pine nuts are currently highly prized (average price of 2,100€ $\mathrm{t}^{-1}$ ) in international markets (Mutke et al. 2005). Edible nuts have become the most important forest product in many rural areas. Sustainable development of the stone pine forest and the surrounding rural areas requires more intensive management of forest resources in order to achieve maximum value per tree.

For these reasons, when nut production is the main goal the target of stone pine management, thinnings must aim low densities to encourage crown development and to avoid overlaps and reduction of the crowns. Also, thinnings must promote tree cone production even if this means a reduction in 
productions per unit area in order to reach greater yield in harvest operations. If there is a delay in thinning treatments or they are too light, productions will not be commercial until the stand is at least 60 years old (Montero et al. 2008). The first thinning must be carried out for achieving low densities since the beginning of fructification (15-25 years old) (Montero et al. 2008).

There are some scientific works which report that fellings favor seed production in pine species, such as Pinus sylvestris L. (Karlsson 2000), Pinus ponderosa Dougl. Ex P.\&C. (Krannitz and Duralia 2004), or Pinus resinosa (Sol. Ex Aiton) (Cooley 1970). The effects of density on cone production in managed stands have been studied in $P$. pinea $\mathrm{L}$ stands (e.g., Calama et al. 2008). However, there are no any studies which have analyzed the thinning schedules and goal densities for each site index and age in the case where the edible pine nut is the main stand aim.

However, large crops fluctuate significantly over the years. The fluctuation is attributed to meteorological conditions (Calama et al. 2011; Mutke et al. 2005) and is associated with the secondary effect of exhaustion of resources caused by large crops (Mutke et al. 2005). Climate conditions affect the physiological cone development and, therefore cone production, in the course of its long reproductive cycle, which takes 3 years. Hot points of cone development are bud formation and flower survival; all of them are closely related to rainfall (Mutke et al. 2005). In addition, both cone and seed production for a given year are also conditioned by the vigor and health of the tree, its size, the loss of seed through pests or predation, soil attributes, mainly water soil retention, and the attributes of the stand, especially the stand density (Calama et al. 2008, 2011).

Diameter is positively correlated with crown size (Ciancio et al. 1986) and cone production (Calama et al. 2008, 2011; Krannitz and Duralia 2004). Since trees of larger diameter produce the most of the cones, increased cone production may be a longer-term benefit of thinning (Krannitz and Duralia 2004). Therefore, large diameters will be required to maximize cone and edible nut productions per tree. Tree growth is regulated by thinning which controls stand density (Mäkinen and Isomäki 2004b). There are many studies about the thinning intensity and growth response, mainly in Northern conifers (e.g., Mäkinen and Isomäki 2004a, b; Slodicak et al. 2005). In the Mediterranean basin, several thinning experiments have been carried out on other pines (e.g., Del Río et al. 2008; Montero et al. 2001). However, there is less information about the effect of first thinning on stone pine (Gordo et al. 2009).

The main objective of this study is to analyze the effect of the first thinning on growth at single tree and stand levels, and on cone production, while taking climatic variables into account, for stone pine stands established through artificial regeneration in the Northern Plateau, which is one of the most important areas for the species in Spain. Considering our data series, the results of this work might be useful in order to determinate the optimum goal density after first thinning. We hypothesize that diameter growth and cone production will be higher in thinned stands than in control stands. Also, we expect to find a positive correlation between cone production and precipitation.

\section{Materials and methods}

\subsection{Experimental design}

A thinning trial with permanent plots was installed in the Pinar $y$ Dehesa de Abajo forest (Valladolid Province, Northern Plateau, Spain) (Fig. 1) in 2004, when the stand was 20 years old. The trial is located in a pure $P$. pinea stand established through artificial regeneration. Annual precipitation in the area is $408 \mathrm{~mm}$, and average annual temperature is $11^{\circ} \mathrm{C}$. The stand is on sandy flat soil at an altitude of around $743 \mathrm{~m}$ above sea level. This area is in the climatic limit of the species because of the shortage of precipitation and the extremely high summer temperatures.

The thinning trial was carried out using a randomized complete block design, with three blocks and three treatments per block. The plots, nine $2,500 \mathrm{~m}^{2}$ adjacent squares $(50 \mathrm{~m} \times 50 \mathrm{~m})$, were thinned from below immediately after trial establishment eliminating small trees, trees with badly shaped crowns, twisted stems, and less vigorous and dominated trees providing remaining trees enough growing space and water and nutrients which are scarce in these sandy soils. Selection of future or elite trees was rejected because the stand was too young at the installation moment. Three treatments were tested: heavy thinning (goal density 275 trees $\mathrm{ha}^{-1}$ ), moderate thinning (goal density 350 trees $\mathrm{ha}^{-1}$ ), and control $\left(517\right.$ trees $\left.\mathrm{ha}^{-1}\right)$. Due to the differences in dominant height, three blocks were established. The dominant heights of the blocks I, II, and III were 6.68, 7.20, and $7.82 \mathrm{~m}$, respectively. The block effect is due to the difference of sand stored in the soil which is related to the water retention in the soil. The average attributes of the stand treatments are shown in Table 1.

All trees in the nine plots are identified in order to facilitate data gathering. Six inventories (2004, 2007, 2009, 2010, 2011, and 2012) were carried out, and the following data were collected: diameter at breast height ( $\mathrm{dbh}$ ) of all trees, the height of 30 trees proportionally situated throughout the diametric distribution, and the height of the ten broadest trees per plot in order to estimate the dominant height $\left(H_{\mathrm{o}}\right)$.

In addition, cones from the trees used to calculate the average height were collected (30 trees per plot proportionally situated throughout the diametric distribution), counted, and quantified their fresh weight each autumn between 2005 and 2012. They were classified into healthy and unhealthy cones. Unhealthy cones were attacked by Dioryctria mendacella Stgr. (Lepidoptera) and Pissodes validirostris Gyll. (Coleoptera). 


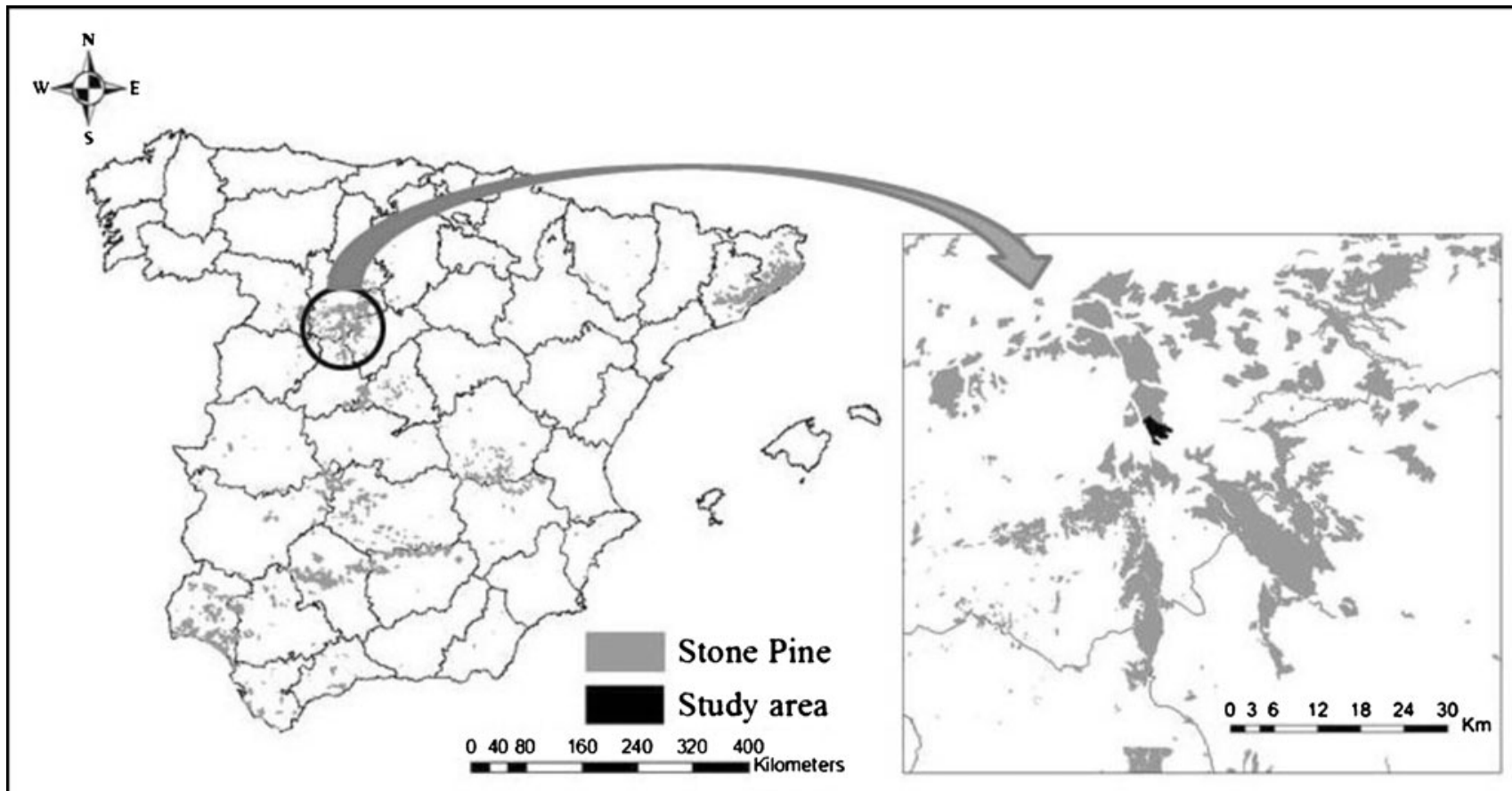

Fig. 1 Distribution of $P$. pinea stands in Spain and the location of the study area

\subsection{Dependent variables}

The effect of different thinning intensities on growth was evaluated by analyzing both stand and average tree attributes as dependent variables. The variables analyzed were as follows: $d i$, tree diameter increment (in millimeter per year) (diameter increment of each single tree); $h i$, height increment (in centimeter per year) (height increment of each single tree); $H_{\mathrm{o}}$, dominant height (in meter); $H_{\mathrm{o}} I$, dominant height increment (in centimeter per year); $D g$, quadratic mean diameter (in centimeter); $D g I$, quadratic mean diameter increment (in centimeter per year); $G$, basal area (square meter per hectare); and $G I$, basal area increment (square meter per hectare per year).

In order to evaluate the effect of the three treatments on the cone production, the following variables were analyzed: $n \_$healthy (number of healthy cones per tree) and $w \_$healthy (weight of healthy cones per tree).

\subsection{Statistical analysis}

The available data consisted of repeated observations of a variable taken from the same tree, block, and plot during different years. Measurements taken on the same tree are more highly correlated than measurements taken on different trees, and measurements taken closer in time on the same tree are more highly correlated than measurements taken further apart in time. This pattern of correlation between observations implies that assumptions about error variance being independent and homogenous are no longer valid (Littell et al. 2000; Wolfinger 1996). The analysis of repeated measurements requires that correlations between the observations made on the same subject be taken into account as well as possible heterogeneous variances among observations on the same tree over time. In this study, this is achieved using a mixed linear model specifying a model for the covariance structure of the data.

Table 1 Average attributes of the stand treatment before and after thinning treatment at the installation year and quantification of the thinning developed

\begin{tabular}{|c|c|c|c|c|c|c|c|c|c|c|c|}
\hline \multirow[t]{2}{*}{ Treatment } & \multicolumn{4}{|c|}{ Before thinning } & \multicolumn{3}{|c|}{ Stand removed } & \multicolumn{4}{|c|}{ After thinning } \\
\hline & $H_{\mathrm{o}}$ & $N$ & $\mathrm{Dg}$ & $G$ & $N$ & $\mathrm{Dg}$ & $G$ & $H_{\mathrm{o}}$ & $N$ & $\mathrm{Dg}$ & $G$ \\
\hline Control & 7.13 & 517 & 15.18 & 9.34 & - & - & - & 7.13 & 517 & 15.18 & 9.34 \\
\hline Moderate & 7.09 & 456 & 15.50 & 8.59 & 104 & 11.17 & 1 & 7.09 & 352 & 16.55 & 7.59 \\
\hline Heavy & 7.48 & 521 & 15.54 & 9.87 & 239 & 12.45 & 2.92 & 7.48 & 282 & 17.69 & 6.95 \\
\hline
\end{tabular}

$H_{o}$ dominant height (in meter), $N$ density (in trees per hectare), $D g$ quadratic mean diameter (in centimeter), $G$ basal area (in square meter per hectare) 


\subsubsection{Thinning effects on growth}

The hypotheses of no differences among thinning treatments averaged over the six inventories and whether their effects change over time or not were tested using the following analysis of variance (ANOVA) mixed model:

$y_{i j k l}=\mu+w_{i}+h_{j}+w h_{i j}+b_{l}+S_{l k}+b h_{i j}+\varepsilon_{i j k l}$

where $y_{i j k l}$ indicates the value of the response variable taken in the sampling unit (tree or plot) $k$ with treatment $i$, located in a block $l ; \mu$ represents the intercept of the model or overall mean; $w_{i}$ is the fixed effect treatment $i ; h_{j}$ is the fixed time effect (periods between inventories for increments and inventories for growth); $w h_{i j}$ is the fixed interaction effect corresponding to treatment $i$ and time $j ; b_{l}$ is the random effect of block $l ; s_{l k}$ is the random sampling unit effect $k$ in block $l$; and $b h_{l j}$ is the random interaction corresponding to blocks and time $j . b_{l}, s_{l k}$, and $b h_{l j}$ are random effects following a normal distribution with mean zero and variance $\sigma_{b}{ }^{2}, \sigma_{s}^{2}$, and $\sigma_{b h}{ }^{2}$, respectively. Finally, $\varepsilon_{i j k l}$ is a random error term defining within-subject pattern of variability. In the case of tree diameter increment $(d i)$, the diameter at the beginning of the period $\left(d_{k j}\right)$, i.e., previous diameter inventory, was taken as covariate.

Model (1) represents the complete model. The simplest structure, including only the fixed part of the model and without random effects, was compared with more complicated models with random structures. Contrasts were performed by applying restricted log-likelihood test after restricted maximum likelihood estimation. Variance-covariance structures for within-subject observations were then evaluated on the basis of the log-likelihood ratio test and Akaike's information criterion (AIC): variance components, compound symmetry (CS), autoregressive order 1, Huyhn-Feldt (H-F), and unstructured (UN). In order to explore the data in more detail, significant ANOVA effects were further investigated using Tukey's post hoc test. All analyses were carried out using SAS 9.2 Proc MIXED (SAS 2009).

\subsubsection{Thinning effects on cone production}

As stated above, cone crops fluctuate over the years, and fluctuation can be mainly attributed to meteorological conditions of the 3-year reproductive cycle. Stone pine bud formation takes place 3 years before cone maturation (Mutke et al. 2005), and therefore thinning effects (more resource availability) do not appear until 3 years after thinning treatment, i.e., cones harvested in 2005 and 2006 came from female flowers sprouted in 2003 and 2004, and buds were formed the previous year during 2002 and 2003, respectively, before thinning treatment. To take these two issues into account, we evaluate the influence of thinning treatment on cone production by a linear mixed model including the modeling data number and the weight of healthy cones per tree and year from 2007 to 2012, and rainfall variables related to key points of cone formation and development. The number and weight of healthy cones do not follow a normal distribution because of the dramatic number of zeros, $81.41 \%$ from 2007 to 2012. First, a logistic regression was used to estimate the probability of finding a cone in a tree according to thinning intensity, and then the influence of treatment on crop was evaluated only for the nonzero events.

We used logistic regression to model the probability that a tree $i$ produces at least one cone in a single year $j$. The dependent variable $n$ healthy (number of healthy cones per tree) was transformed into a binary variable logged bin where value " 1 " implies $n$ healthy $>0$ and " 0 " implies $n$ health $y=0$. We used a generalized linear mixed model with a logit link function, random effects and repeated measures to test the effects of explanatory variables on the binary cone production data. Let $\pi_{k}$ be the probability of $n \_$healthy $>0$ and $1-\pi_{k}$ as the probability that a tree produces no cone. Odds is defined as $\pi$ / $(1-\pi)$.

$\log i t(\pi)=\log \left(\frac{\pi}{1-\pi}\right)=\mu+w_{i}+\alpha x_{i j k l}+b_{l}+s_{l k}+\varepsilon_{i j k l}$

All the model parameters have been defined previously, except $x$ which represents vectors of covariates (corresponding to different levels depending on the covariate), and $\alpha$ which represents vectors of the unknown but estimable parameters. We included as covariates the stand age and some rainfall variables (data series from the nearest weather station of the State Meteorological Agency (AEMET 2012)): (a) sum of May and June, and October and November precipitation 3 years before maturation ( $P m j$ and $P o n$, respectively). $P m j$ is related to the formation of buds and Pon, to the differentiation of buds into flower and growth buds; (b) summer precipitation after flowering and conditions the survival of flowers $(P s)$; and (c) the sum of winter-spring months precipitation before maturation $(P w s)$, which influences cone weight. In addition, we incorporated diameter at breast height $d b h$ as covariate since the diameter is positively correlated with cone production (Calama et al. 2008, Calama et al. 2011; Krannitz and Duralia 2004).

Moreover, the model can also be interpreted as the log of odds back to the probability such that

$\pi_{i j l k}=\frac{e^{\mu+w_{i}+\alpha x_{i j k l}+b_{l}+s_{l k}+\varepsilon_{i j k l}}}{1+e^{\mu+w_{i}+\alpha x_{i j k l}+b_{l}+s_{l k}+\varepsilon_{i j k l}}}$

For any given value of $\mu+w_{i}+\alpha x_{i j k l}+b_{l}+s_{l k}+\varepsilon_{i j k l}, \pi_{i j k l}$ values (probability of finding a cone in a tree $k$ with treatment $i$, in the block $l$ and the year $j$ ) are always between 0 and 1 . Therefore, we only get sensible realizations (Zuur et al. 2009).

Analysis was conducted using SAS 9.2 Proc GLIMMIX (SAS 2009). In order to avoid over-parameterization, an 
iterative sequential procedure was proposed to define the appropriate model for each response variable. Firstly, the simplest structure with only the treatment as fixed effect and without random effects was compared with more complicated models with random structures. Inclusion of random effects and selection of covariance matrix followed the same procedures described for growth models. Once the preliminary random structure was selected and the within-subject covariance matrix was chosen, the inclusion of covariates was evaluated in terms of the log-likelihood ratio test, applied after a pseudo-maximum likelihood estimation. When the structure had been defined, the model was fitted following residual likelihood. The disadvantage of the pseudo-likelihood is the absence of a true log-likelihood, which complicates model comparisons and model selection based on information criteria (Schabenbeger 2007). The GLIMMIX procedure implements two integral approximation techniques to marginal likelihood: Laplace's method and quadrature approximation which do not allow R-side random effects (SAS 2009), and therefore, they do not tolerate repeated measures.

Once the probability that a tree produces no cone was modeled, the effect of thinning treatments on cone production was evaluated using nonzero weight cone values. Weight values, even when not considering zero events, do not follow a normal distribution, so a logarithmic transformation was employed. The proposed mixed model was

$\log \left(C_{i j k l}\right)=\mu+w_{i}+\alpha x_{i j k l}+b_{l}+s_{l k}+\varepsilon_{i j k l}$

where $C_{i j k l}$ is the weight of cone production for a tree $k$ with treatment $i$, in the block $l$ and the year $j$. All the parameters have been defined above. The methodology for model building was the same as used for the probability logistic model but using true likelihood. Analysis was carried out using Proc MIXED (SAS 2009).

\section{Results}

\subsection{Thinning effects on growth}

In the case of tree diameter increment, treatment, time, and the interaction of treatment $\times$ time were statistically significant $(p$ value $<0.0001$ for all of them), indicating that trees with different thinning treatments had different diameter growth rates over time. Further analysis indicated that tree diameter growth was greater in thinned plots than in control plots in the second, fourth, and fifth growth intervals, but we did not find significant differences between moderate and heavy thinning (Fig. 2). The tree diameter increments were decreasing since thinning development (2004) to the last inventory (2012) except in the fourth period (2010-2011) when the highest increments were found. Moreover, the diameter at the beginning of

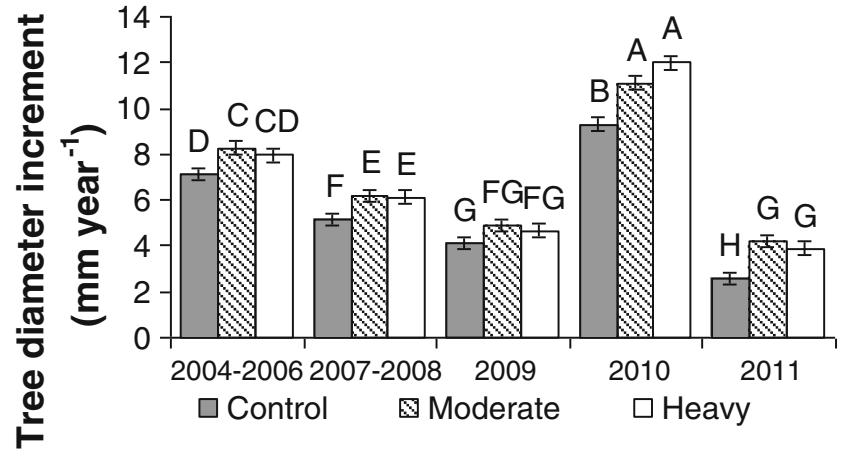

Fig. 2 Average and standard error of tree diameter increment according to type III test for fixed effects. Treatments marked with same letter are not significantly different $(p$ value $>0.05)$

each period was also significant ( $p$ value $=0.0045)$. It had a weak negative influence (estimation coefficient $=-0.00331$ ) on tree diameter growth, i.e., increments were larger when tree diameters were thin. The values of tree diameter increment were higher in released stands than those trees located in unthinned stands. Concerning the random effect, the block was significant in terms of the log-likelihood ratio test. The best structure for within-subject covariance was the UN matrix indicating the existence of a common pattern associated with the tree effect, but no clear trends of correlation among tree observations (Littell et al. 1996).

In the case of tree height increment, treatment and time were also found to be statistically significant ( $p$ value $=0.0260$ and $p$ value $<0.0001$, respectively). However, interaction treatment $\times$ year was not significant ( $p$ value $=0.1505)$, indicating that effect of thinning is constant in time. Significant differences only appeared between heavy thinning and control treatment. Block effect also improved the model in terms of the loglikelihood ratio test. The Huyhn-Feldt structure for the variance-covariance matrix (H-F) reached the lowest AIC value.

As regards plot variables, thinning treatment and time had significant effects on basal area and quadratic mean diameter ( $p$ value $>0.0001$ for both effects), but the interaction treatment $\times$ year did not $(p$ value $=0.8286$ and $p$ value $=0.2514$, respectively). The effect of thinning in both variables was inverse; thinning significantly decreased the basal area while increasing the quadratic mean diameter. In both variables, the block random effect was included, and the UN matrix was selected as the best covariance structure.

The remaining variables analyzed were not statistically influenced ( $p$ value $>0.05$ ) by the treatment or treatment $\times$ time, and results are not shown.

\subsection{Thinning effects on cone production}

The cone production, once extrapolated that taking into account 30 sampled trees per plot were proportionally selected throughout the diametric distribution, the average production of the control, moderate, and heavy plots was $34.4,50.8$, and 
$43.4 \mathrm{~kg} \mathrm{ha}^{-1}$ year $^{-1}$, respectively, since 2005-2012. Regarding modeling data, from 2007 to 2012, the control plots produced $14.9 \mathrm{~kg} \mathrm{ha}^{-1}$ year $^{-1}$; the plots with moderate thinning, $39.3 \mathrm{~kg} \mathrm{ha}^{-1}$ year $^{-1}$; and the plots with heavy thinning, $32.8 \mathrm{~kg} \mathrm{ha}^{-1}$ year $^{-1}$. Figure 3 shows the average cone production per plot and years according to the three treatments. It can be seen that there was great variability among the years. Both the number and weight of cones oscillated with minima in 2007 and 2012 and peaks in 2005, 2006, and 2009 (Fig. 3). The weight per cone behaved similarly; it ranged from 0.198 to $0.255 \mathrm{~kg}$ per cone. From 2005 to 2012, $76.22 \%$ of the observations were null, i.e., at least one cone was found in only $23.78 \%$ of the measurements. Furthermore, more than $70 \%$ of the trees produced at least one cone during the period of 2005-2012.

Concerning the probability of finding at least one cone in a given tree, the final chosen model contained just the treatment as fixed effect. In terms of pseudo-likelihood, none of the covariates analyzed improved the model (Table 2), and therefore, they were not included in the final model. The ratio of the generalized chi-square statistic and its degrees of freedom was 0.90 , indicating that the variability in this data has been properly modeled and that there was no residual overdispersion (Schabenberger 2007). The best covariance structure was CS pointing out a constant correlation among tree observations. The treatment effect was significant for the probability of finding cones in a tree $(p$ value $<0.0001)$. No significant differences between heavy and moderate thinning were found ( $p$ value $=0.9939$ ). In both cases, the probability of finding at least one cone in a tree is about $23 \%$. This probability is reduced by half in the control treatment, with significant differences between thinned plots and control plots appearing ( $p$ value $<0.0001$ for both contrasts) (Table 3 ).

There was a significant effect of treatment $(p$ value $=0.0488)$ on the logarithm of nonzero weight cone values. The most productive treatments were heavy and moderate thinning. However, Tukey's test did not reveal significant differences between both thinning treatments $(p$ value $=0.9933)$. Heavy thinning was different from control treatment $(p$ value $=0.0114$ ). Also, significant differences appeared between moderate thinning and control $(p$ value $=0.0131)$. Ps, summer precipitation after flowering, was the only rainfall co-variable that showed statistically significant influence $(p$ value $=0.0040)$ on cone

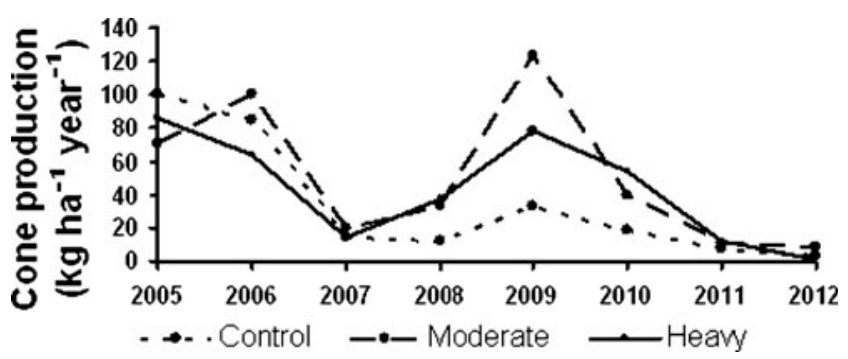

Fig. 3 Average cone production per hectare according to treatment after extrapolation of 30 selected trees per plot cone production
Table 2 Estimates of the fixed effects parameters and covariance components for cone production variables (only shown for significant effects $p$ value $<0.05)$. $p$ values are referred to type III test for fixed effects

\begin{tabular}{lcll}
\hline Source & Probability & Source & $\begin{array}{l}\text { Log of } \\
\text { weight } \\
\text { cones }\end{array}$ \\
\hline $\begin{array}{c}\text { Fixed parameters } \\
\text { Intercept }\end{array}$ & -2.2391 & Intercept & \\
Heavy & 1.0287 & Heavy & 2.0327 \\
Moderate & 1.0474 & Moderate & 0.1382 \\
Control & 0 & Control & 0.1342 \\
& & $P S$ (summer precipitation) & 0.002050 \\
& & $d b h$ & 0.001577 \\
Covariance component & Block & 0.007337 \\
Tree-CS & 0.02231 & Tree-CS & 0.06578 \\
& & $p$ value treatment & 0.0084 \\
$p$ value treatment & $<0.0001$ & $p$ value $P S$ & 0.0040 \\
& & $p$ value $d b h$ & 0.0010 \\
\hline
\end{tabular}

production (Table 2). Finally, diameter at breast height, $d b h$, also appeared as significant $(p$ value $=0.0010)$. Both co-variables showed a positive influence on stone pine cone production.

\section{Discussion}

\subsection{Thinning effects on growth}

In this study, two thinning treatments (moderate and heavy) and one control were applied in a 20-year-old $P$. pinea stand. As expected, thinning favored diameter growth. Similar results were found for other pine stands between 20 and 30 years old (Cooley 1970; Guller 2007; Peltola et al. 2007; Pukkala et al. 1998). However, we found significant differences among unthinned plots and thinned plots, but no any difference appeared between thinning regimes. This might be a consequence of the soft difference between both thinning goal densities. A heavier thinning could show larger tree diameter increments. In younger stands than ours, the effect of precommercial thinning already produced diameter growth increments in stone pine (Gordo et al. 2009). We suggest that the cause of the appearance of the largest tree diameter increments 6 years after the thinning development (during 2010-2011) is the high rainfall registered in 2010 .

The diameter at the beginning of the period was significant, in that the smallest trees had the greatest diameter growth. The growth model of Calama and Montero (2005) for stone pine included diameter at breast height as a negative effect on tree diameter increment. Pukkala et al. (1998) also found that thin trees showed larger diameter growth. Peltola et al. (2007) reported that regardless of thinning intensity, the small- and 
Table 3 Probability mean and its confidence limits and least squares mean estimate on logit scale and its $95 \%$ confidence limits

Different letters indicate significant differences ( $p$ value $<0.05$ ) according to Tukey's test

\begin{tabular}{llllllll}
\hline Treatment & \multicolumn{2}{l}{ Probability scale } & & \multicolumn{3}{l}{ Logit scale } \\
\cline { 2 - 3 } & Mean & Lower mean & Upper mean & & Estimate & Lower & Upper \\
\hline Heavy & $0.2296(\mathrm{~A})$ & 0.1890 & 0.2761 & & -1.2104 & -1.45680 & -0.9640 \\
Moderate & $0.2330(\mathrm{~A})$ & 0.1916 & 0.2801 & & -1.1917 & -1.43960 & -0.9438 \\
Control & $0.0963(\mathrm{~B})$ & 0.0698 & 0.1315 & & -2.2391 & -2.5904 & -1.8877 \\
\hline
\end{tabular}

medium-sized trees grew more in relative terms in response to the thinning than the largest trees. However, they found that the largest trees grew more in absolute terms.

\subsection{Thinning effects on cone production}

In this study, we analyzed crop weight per tree which is a function of both the number of cones per tree and their weight. The number of cones is the counting data, and its statistical problems have been described above. The use of the probability of finding a cone in a tree allowed to complement the effect of thinnings on crop weight. To this end, we used logistic regression. Logistic regression techniques have been used in the field of forestry to predict mortality (Adame et al. 2010; Bravo-Oviedo et al. 2006), ingrowth (Adame et al. 2010), and fruit and cone production (Calama et al. 2011). We found that thinning favored the probability of finding at least one cone in a given tree, being more than the double in the thinned than in control plots.

The fact that bud formation takes place 3 years before maturation and the thinning treatment was carried out in 2004 implies that cones harvested in 2006 and 2005 came from buds formed before the thinning treatment. Therefore, the harvest of 2007 is the first one to be considered under thinning effects. Until 2007, the differences between treatments were weak, and since 2007, control plots showed lower production. This was more evident in bumper crop years, where the difference between thinned and control plots was larger. Overall, the greatest cone production appeared in thinned plots, reaching more than twice the production in thinned stands than control stands. Reukema (1961) found a similar result. He reported that thinned stands of young Douglas fir produce much more seed than unthinned stands in good years, but thinning does not stimulate seed production in poor seed years. At the end of our study period, trees located in thinned plots produced almost two times the number of cones, and they reached double of the cone production in weight. In a 20-year-old $P$. resinosa plantation on a good site, Cooley (1970) reported that the number of mature cones per tree was increased 2 years after thinning. Our results are also in concordance with Karlsson (2000), who studied on seed production of mature Scots pine stands after release cutting. His results showed that released trees produce much more cones than the unreleased. Thinning treatment allows crowns to be exposed to more light, and the availability of water and mineral nutrients is higher (Karlsson 2000; Krannitz and Duralia 2004) because of less inter-tree competition. Actually, Gonçalves and Pommerening (2012) found an inhibition of cone production between trees close in space and stimulation at larger distances. However, we did not find important differences between the two thinning regimes. We suggest a small difference between heavy and moderate intensities and, therefore, the development of heavier thinnings to promote larger crops per tree. Moreover, more trials are needed to find out when first thinning should be carried out in each site index.

Although we did not find differences in cone production between moderate and heavy treatments, the harvest effectiveness is higher in heavily thinned plots, since production is located in an area with fewer trees, and, in this way, both manual and mechanized harvesting reach greater yields.

When we carried out the statistical analysis by performing mixed model with the log of cone weight production being the dependent variable, differences between treatments appeared with the significant difference between the thinned treatments and control plots. Log transformation was already used by other authors (Calama and Montero 2007; Mutke et al. 2005) to study on stone pine cone production. However, instead of removing null weight values to perform statistical analysis, they applied the log transformation of the cone weight plus 1 to delete zero values since they were studying on older stands than ours, which were more productive, and null values were shorter.

Regarding the effect of climatic variables on the log of cone weight production, the only variable that appeared as significant was the $P s$, summer precipitation after flowering, related to flower survival and, therefore, number of cones. The other rainfall variables (Pmj, Pon, and Pws) are related to bud survival and cone fattening. In older stands, Calama et al. (2011) found all of rainfall variables considered in our study to be statistically significant. Mutke et al. (2005) studied on meteorological effects on cone production in mature stands of stone pine. They found that cone production was significantly affected by winter/ spring rainfall before primordia formation (3 years before cone maturation), rainfall in October 3 years before cone maturation, rainfall of winter/spring before pollination, and the annual rainfall before cone ripening. Null influence of these precipitation variables can be explained by short data series, and the fact that pines are young and they did not reach normal and regular cone productions. We suggest that the stands were quite young, and root competition between trees was weak. 
Despite of our short data series, we consider that it is enough to compare the effect of the thinnings over the whole study period (not over individual years) since we did not want to identify those factors characterizing masting, or describe a pattern of annual production which has already been studied (e.g., Calama et al. 2011).

Finally, we found a positive effect of diameter at breast height with cone production. This is in concordance with other authors (Calama et al. 2008, 2011; Krannitz and Duralia 2004). Therefore, thinning treatments, on one hand, reduced the density, decreasing inter-tree competition and favoring cone production, and on the other hand, increased diameter growths and, hence, promoted larger crops.

We observed a positive effect of the density reduction on the growth of young stone in artificially regenerated pine stands. Also, cone production increased by employing early thinning treatments. However, we did not find significant differences between moderate and heavy thinning both on tree diameter growth and cone production, and, despite of our short data series, our results suggest to carry out heavier thinnings to favor individual tree cone production. Wider knowledge about starting thinning age in each site index is necessary.

Acknowledgments The authors wish to thank Dr. Nicholas Devaney (National University of Ireland, Galway) for revising the English writing; Ángel Bachiller for gathering data; and Castilla y León Forest Service, especially to the forest rangers of Viana de Cega region, for allowing plot installation and maintenance. We also thank the two anonymous reviewers for valuable suggestions and comments on the manuscript.

Funding This work was part of the Research Project AT2010.007 and AGL 2010.21153.01.

\section{References}

Adame P, del Río M, Cañellas I (2010) Ingrowth model for pyrenean oak stands in north-western Spain using continuous forest inventory data. Eur J For Res 129:669-678. doi:10.1007/s10342-010-0368-1

AEMET (2012) State Meteorological Agency. www.aemet.es. Accessed 11 Feb 2013

Bravo-Oviedo A, Sterba H, del Río M, Bravo F (2006) Competition-induced mortality for Mediterranean Pinus pinaster Ait. and P. sylvestris L. For Eco Manag 222:88-98. doi:10.1016/j.foreco.2005.10.016

Calama R, Montero G (2005) Multilevel linear mixed model for tree diameter increment in stone pine (Pinus pinea): a calibrating approach. Silva Fenn 39:37-54

Calama R, Montero G (2007) Cone and seed production from stone pine (Pinus pinea L.) stands in Central Range (Spain). Eur J For Res 126:23-35. doi:10.1007/s10342-005-0100-8

Calama R, Mutke S, Gordo J, Montero G (2008) An empirical ecologicaltype model for predicting stone pine (Pinus pinea $\mathrm{L}$.) cone production in the Northern Plateau (Spain). For Ecol Manag 255:660-673. doi:10.1016/j.foreco.2007.09.079

Calama R, Mutke S, Tomé JA, Gordo FJ, Montero G, Tomé M (2011) Modelling spatial and temporal variability in a zero-inflated variable: the case of stone pine (Pinus pinea L.) cone production. Ecol Model 222:606-618. doi:10.1016/j.ecolmodel.2010.09.020
Ciancio O, Cutini A, Mercurio R, Veracini A (1986) Sulla struttura della pineta di pino domestico di Alberese. Ann Ist Sper Selv, Arezzo 17:169-236 [In Italian]

Cooley JH (1970) Thinning and fertilizing Red pine to increase growth and cone production. North Central Forest Experiment Station, US Forest Service, St. Paul, 8 pp

del Río M, Calama R, Cañellas I, Roig S, Montero G (2008) Thinning intensity and growth response in SW-European Scots pine stands. Ann For Sci 65:308. doi:10.1051/forest:2008009

Gordo J, Calama R, Rojo LI, Madrigal G, Álvarez D, Mutke S, Montero G, Finat L (2009) Experiencias de clareos en masas de Pinus pinea L. en la Meseta Norte. In: Summaries of the Spanish fifth forestry congress. S.E.C.F.-Junta de Castilla y León [In Spanish]

Gonçalves AC, Pommerening A (2012) Spatial dynamics of cone production in Mediterranean climates: a case study of Pinus pinea L. in Portugal. For Eco Manag 266:83-93. doi:10.1016/j.foreco.2011.11.007

Guller B (2007) The effects of thinning treatments on density, MOE, MOR and maximum crushing strength of Pinus brutia Ten. wood. Ann For Sci 64:467-475. doi:10.1051/forest:2007024

Karlsson C (2000) Seed production of Pinus sylvestris after release cutting. Can J For Res 30:982-989. doi:10.1139/x00-035

Krannitz PG, Duralia TE (2004) Cone and seed production in Pinus ponderosa: a review. Wes North Am Naturalist 64:208-218

Littell RC, Milliken GA, Stroup WW, Wolfinger RD (1996) SAS ${ }^{\circledR}$ system for mixed models. SAS Institute Inc, Cary, p 633

Littell RC, Pendergast J, Natarajan R (2000) Tutorial in biostatistics: Modelling covariance structure in the analysis of repeated measures data. Stat Med 19:1793-1819

Mäkinen H, Isomäki A (2004a) Thinning intensity and growth of Scots pine stands in Finland. For Eco Manag 201:311-325. doi:10.1016/j. foreco.2004.07.016

Mäkinen H, Isomäki A (2004b) Thinning intensity and growth of Norway spruce stands in Finland. Forestry 77:349-364. doi:10.1093/ forestry/77.4.349

Montero G, Calama R, Ruiz-Peinado R (2008) Selvicultura de Pinus pinea L. In: Serrada R, Montero G, Reque JA (eds). Compendio de Selvicultura Aplicada en España. INIA-Ministerio de Educación y Ciencia. Madrid, Spain 1178 pp [In Spanish]

Montero G, Cañellas I, Ortega C, del Río M (2001) Results from a thinning experiment in a Scots pine (Pinus sylvestris L.) natural regeneration stand in the Sistema Ibérico Mountain Range (Spain). For Eco Manag 145:151-161. doi:10.1016/s0378-1127(00)00582-X

Mutke S, Gordo J, Gil L (2005) Variability of Mediterranean stone pine cone production: yield loss as response to climate change. Agric For Meteorol 132:263-272. doi:10.1016/j.agrformet.2005.08.002

Peltola H, Kilpeläinen A, Sauvala K, Räisänen T, Ikonen VP (2007) Effects of early thinning regime and tree status on the radial growth and wood density of Scots pine. Silva Fenn 41:489-505

Pukkala T, Miina J, Kellomäki S (1998) Response to different thinning intensities in young Pinus sylvestris. Scand J For Res 13:141-150

Reukema DL (1961) Seed production of Douglas-fir increased by thinning. PNW Old Series Research Note 210:1-5

SAS (2009) SAS/STAT ${ }^{\circledR} 9.2$ user's guide, 2nd edn. SAS Institute Inc., Cary

Schabenberger O (2007) Growing up fast: SAS ${ }^{\circledR} 9.2$ enhancements to the GLIMMIX procedure. SAS Global Forum 2007. Paper 177-2007

Slodicak M, Novak J, Skovsgaard JP (2005) Wood production, litter fall humus accumulation in a Czech thinning experiment in Norway spruce (Picea abies (L.) Karst.). For Eco Manag 209:157-166. doi:10.1016/j.foreco.2005.01.011

Wolfinger RD (1996) Heterogeneous variance-covariance structures for repeated measures. J Agr, Biol Envir St 1:205-230

Zuur AF, Ieno EN, Walker N, Saveliev AA, Smith GM (2009) Mixed effects models and extensions in ecology with R. Statistics for biology and health. Springer, New York, 574 pp 